\title{
Sobre a categoria da mediação em Adorno ${ }^{1}$
}

\author{
Antônio Marcos V. Sanseverino ${ }^{2}$ \\ (Universidade Federal do Rio Grande do Sul)
}

\begin{abstract}
RESUMO: O PRESENTE ESTUDO TOMA COMO CENTRO O MODO COMO THEODOR ADORNO DEFINE A MEDIAÇÃO ENTRE ARTE E SOCIEDADE. O PASSO SEGUINTE É VERIFICAR O MODO COMO ESSA CATEGORIA APARECE EM DIVERSOS ENSAIOS DO AUTOR: ENSAIO COMO FORMA; PALESTRA SOBRE LÍRICA E SOCIEDADE; POSIÇÃO DO NARRADOR NO ROMANCE CONTEMPORÂNEO ENTRE OUTROS. O INTERESSE É EVIDENCIAR O MOVIMENTO DE LEITURA DE ADORNO, QUE, AO ESTABECER A PRIMAZIA DO OBJETO, DESENTRANHA A MEDIAÇÃO DO PRÓPRIO OBJETO E IMPEDE A RECEPÇÃO IMEDIATA DA OBRA DE ARTE.
\end{abstract}

ABSTRACT: THE PRESENT STUDY FOCUSES ON HOW THEODOR ADORNO DEFINES MEDIATION BETWEEN ART AND SOCIETY AND TRIES TO FOLLOW UP HOW THIS CATEGORY APPEARS IN SOME OF THIS AUTHOR'S ESSAYS ("THE ESSAY AS A FORM", "ON LYRIC POETRY AND SOCIETY", "THE POSITION OF THE NARRATOR IN THE CONTEMPORARY NOVEL", AMONG OTHERS). THE INTEREST, HERE, IS TO SHOW ADORNO'S READING MOVEMENT, WHICH, ESTABLISHING THE OBJECT'S PRIMACY, REVEALS THE OBJECT'S MEDIATION AND PREVENTS THE ART PIECE'S IMMEDIATE RECEPTION.

PALAVRAS-CHAVE: MEDIAÇÃO - THEODOR ADORNO - TEORIA CRÍTICA. KEY-WORDS: MEDIATION - THEODOR ADORNO - CRITICAL THEORY.

\footnotetext{
1 Este pequeno ensaio considera a categoria da mediação como central para a relação entre arte e sociedade no pensamento de Adorno. Como objeto de análise foram tomados alguns de seus ensaios. Esse é o primeiro passo de uma pesquisa sobre as contribuições do pensamento de Theodor Adorno para a teoria da literatura.

2 Professor Adjunto de Literatura Brasileira da Universidade Federal do Rio Grande do Sul.
} 
o pensamento de Theodor Adorno, a categoria da mediação traz em primeiro plano a necessidade para a estética da relação entre arte e sociedade. Ele não aponta uma determinação causal da sociedade sobre a obra, nem propõe a existência absoluta da autonomia da arte, pois essa última é uma concepção historicamente datada. Para Adorno, o estudo da arte, no âmbito sociológico, para ser produtivo, deve partir da análise imanente da obra para mostrar como a forma traz em si os condicionantes sociais.

Por fim, quanto à terminologia: o que eu, na Introdução à sociologia da música, chamei de "mediação", não é, como Silbermann supõe, o mesmo que "comunicação”. Sem querer negar minimamente esse elemento filosófico, empreguei lá o conceito de mediação rigorosamente no sentido hegeliano. De acordo com isso a mediação está na própria coisa, não sendo algo que seja acrescido entre a coisa e aquelas às quais ela é aproximada. [...] Em outras palavras, refiro-me à questão muito específica dirigida aos produtos do espírito, relativa ao modo como momentos da estrutura social, posições, ideologias e seja lá o que for conseguem se impor nas próprias obras de arte. (ADORNO, 1986c)

Ao mesmo tempo em que não se pode esquecer "a alteridade constitutiva da arte" (ADORNO, s.d.), a obra traz em si as determinações sociais. Nesse sentido, a arte separa-se da sociedade, mas os antagonismos sociais não resolvidos retornam a ela como problemas imanentes à sua forma. A necessidade da mediação não está em procurar os conteúdos sociais inconscientes tematizados na obra de arte, pois a arte seria desse modo um documento, um sintoma, ou mero índice de algo heterogêneo a ela. A questão, então, é a de saber como um problema exterior torna-se imanente à arte, e como um aspecto formal torna-se um elemento estético.

O trabalho não se propõe a assimilar de um modo linear o objeto dentro do sujeito, de alcançar aquilo que Adorno chama no primeiro de seus três estudos sobre Hegel "a univocidade de uma identidade imediata": o trabalho de mediação da subjetividade é destinado a fluidificar as "determinações endurecidas dos fenômenos", a penetrar as camadas profundas do real, a descobrir as articulações e as ligações dificilmente acessíveis à intuição imediata, mesmo se o termo ad quem permanece no idealismo hegeliano a assimilação da substância 
dentro do sujeito, uma mítica identidade objeto-sujeito. (TERTULIAN, 1984, tradução minha) ${ }^{3}$

Segundo Tertulian, Adorno retira o conceito de mediação da filosofia hegeliana, de sua dialética, que se dirigia no rumo do concreto. "Fluidificar as determinações endurecidas dos fenômenos" para Hegel era compreender os dados particulares da prosa da vida através do conceito que os elevaria ao espírito. O sujeito compreende as contradições internas do objeto ao identificá-las como parte do espírito, construindo assim a unidade sintética da totalidade. É do Espírito que o sujeito necessariamente parte, negando-se nas determinações finitas, abstratas e fragmentárias, para retornar a ele, ao concreto e orgânico. O fenômeno perde sua particularidade enrijecida ao tornar-se membro vivo do espírito. A realidade constrói-se como um processo unitário através das mediações, em que apenas o racional é real. Aquilo que escapa ao conceito, o efêmero, não se constitui um objeto digno da filosofia.

Adorno desfaz o a priori idealista da unidade necessária ao colocar que toda a totalidade seria por natureza totalitária, quer dizer, uma construção que anula o sujeito. A totalidade existiria no mundo real como algo incomensurável. Seria verdadeira, pois ela funciona como o "espírito", o "éter", e ao mesmo tempo falsa, pois a sua razão não é razão, mas manifestação de um interesse particular (ADORNO, 1984). O valor de troca, como termo de comparação, torna quantificáveis todas as formas culturais; e a razão instrumental penetra todos os setores da sociedade humana, reduzindo-os à abstração do dinheiro. Assim, a totalidade é existente, mas não deixa de ser falsa, pois ela não corresponde a uma necessidade humana, apagando qualquer elemento estranho que esteja fora do todo. Há assim uma relação forte entre o conceito, como produtor do idêntico na filosofia, e o valor de troca, como abstração do mesmo na sociedade. Em ambos, o sujeito perde sua especificidade ao ter sua identidade construída na absorção ao todo.

3 "Ce travail ne se propose pas de résorber d'une façon linéaire l'objet dans le sujet, d'arriver à ce qu'Adorno appelle dans sa première des trois études sur Hegel «l'univocité d'une identité immédiate »: le travail de médiation de la subjectivité est destiné à fluidifier les "determinations durcies des phenomènes 》, à pénétrer les couches profondes du réel, à decouvrir des articulations et des rapports difficilement accéssibles à l'intuition immédiate, même si le terme ad quem reste dans l'idéalisme hégélien la résorbtion de la substance dans le sujet, usestane mythique identité objet-sujet." 
Desse modo, para Adorno a totalidade destrói o sujeito e produz a abstração. Como o pensamento subjetivo constrói-se por si mesmo, desligado do objeto, ele acaba por se alienar da realidade na mesma medida em que o positivismo, ao pretender quantificar tudo, acaba por coisificar as relações humanas. Em ambos, seguros de si mesmos, surge a fetichização do conhecimento, que traz dentro de si a queda do homem na barbárie. Nesse momento, o real e o humano ficam para além da totalidade, fora do sistema. O olhar de Adorno lembra o do viajante Jean de Léry que viu e mostrou aos europeus a devoração bárbara de um homem por outro entre os índios, mas, em vez de apenas condená-la, evidenciou como os franceses traziam dentro de sua cultura a própria barbárie, ao construir dogmas e não um conhecimento auto-reflexivo, destruindo, em guerras religiosas, todos aqueles que lhes eram diferentes.

Assim, para Adorno, a tarefa da filosofia, através da mediação, é desapegarse da imediatez (cf. ADORNO, 1984), mostrando como no ato espontâneo ou no imediato encontra-se o mediato. As determinações endurecidas tomam a forma do cotidiano, da espontaneidade, dos gestos irrefletidos. Elas aparentemente são expressões livres do sujeito, mas na verdade representam exemplos particulares do mesmo, da totalidade. Ao fluidificar essas determinações, tomando como objeto o estranho, o diferente, o não-idêntico, a filosofia volta-se para o concreto, mostrando o quanto a totalidade social está dentro dos pequenos gestos cotidianos, automatizados, como fez em Minima moralia.

A relação entre a sociedade de consumo (atomística, marcada pela indústria cultural) e o indivíduo implica a dissolução do sujeito, na medida em que a pessoa singular fica submetida à totalidade na qual se perde. Através da ideologia, o indivíduo se em transforma em objeto, tendo sua alma coisificada, em que mesmo o gesto espontâneo ou irracional traz a marca da dominação servil e alienada ao senhor. Nesse sentido, é lido por Adorno e Horkheimer, como alegoria, o trecho da Odisséia em que Ulisses, amarrado, ouve o canto da sereia, enquanto seus homens, presos aos remos, de cabeças baixas e ouvidos tapados por cera, apenas remam violentamente. $\mathrm{Na}$ divisão do trabalho, o senhor ouve a promessa de integração com a natureza, mas, amarrado, está impotente para responder a ela. Os trabalhadores, identificados ao senhor, ficam surdos, presos a um trabalho alienado. Dentro da dialética do esclarecimento, temos aí a formação não apenas do ego, mas do burguês, que se prende à razão, reprimindose a si e aos outros. A razão, totalitária e identitária, bane o mito para fora de si, 
procurando incorporar tudo dentro do sistema, mas ao negar a natureza acaba por trazer a barbárie e a violência desumana dentro de si.

Em "Educação após Auschwitz" (ADORNO, 1986a), o problema desse campo de extermínio, o seu contínuo terror, não está apenas no fato de ter acontecido, mas no de novamente poder ocorrer, pois não foi um acontecimento anômalo, mas algo coerente ao desenvolvimento da sociedade globalizada. Na frieza, na falta de amor e na indiferença encontra-se a explicação para a aceitação dos crimes nazistas. O gesto frio e a dissolução do sujeito são postos por Adorno dentro da sociedade industrial. Num mundo cuja falsa mediação universal é a mercadoria, tudo passa a ser considerado por seu valor de troca. Assim, cada coisa ganha identidade quando serve de mercadoria, mediação ao lucro. O caráter abstrato, negativamente conceituado por Adorno, apaga qualquer traço heterogêneo que fuja do valor de troca, que, assim, se constitui como a falsa mediação universal.

O caráter sentimental de um filme holywoodiano ou de uma música comercial teria o poder fetichista de alimentar o consumismo burguês, que absorve a obra para ter um veículo em que colocar seus sentimentos (ADORNO, 1986a). O campo de concentração existe não como negação da sociedade capitalista, mas como afirmação radicalmente acentuada da coisificação do homem. Por isso, há que se valorizar a autonomia do sujeito, sua liberdade para escapar da massificação. A reflexão que interrompe a imediatez do gesto irrefletido ou violento revela o seu caráter mediato, expressão cultural e ideológica. No gesto emancipado está a luta contra a barbárie instalada no seio da razão capitalista - Auschwitz não é e é aqui.

Quando Adorno discute a música de mercado (ADORNO, 1983a), coloca um problema semelhante, pois a música passou a ser expressão do mesmo, do interesse, do lucro. É mercadoria que vale por seu valor de troca. A produção, distribuição e consumo são regidos pelo mesmo princípio dominante, levando a uma regressão da audição, que passa a ser vista como distração e desatenção. A partir do conhecimento intrínseco da música, ele mostra como o valor de troca penetrou na estruturação interna da obra, desde sua produção até a fruição do ouvinte. A divisão de tarefas da música, na época em que escrevia o ensaio, dava o caráter primordial ao arranjador cujo princípio básico era o da mutilação da obra original, para uma forma orquestral, que se adequasse ao pretenso gosto do público. Além disto, a matéria torna-se feti- 
che: a voz do solista, o som de um instrumento, a técnica em si mesma ou o virtuose de um saxofone, as partes são mais valorizadas do que a música.

O tempo livre (ADORNO, 1995a), dedicado à "diversão", ao descanso do trabalho rotineiro, transforma-se ele também em padrão do mesmo, em consumo quantificado de uma forma industrial. Nesse ensaio sobre a música, Adorno mostra como a forma musical traz os sinais da ideologia. Nem apolínea (domínio dos instintos pela forma), nem dionisíaca (libertação de forças inconscientes), a música fetichista é fruto da indiferença, cuja natureza prevê uma audição dispersiva que se apega a fragmentos e não consegue ter atenção suficiente para recompor a totalidade da música. O padrão atomístico da sociedade industrial, da divisão do trabalho, reaparece dentro do modo de produção da música de consumo e da sua recepção fragmentária. Ao comentar o jazz, como música de consumo, Adorno chega à mesma conclusão, de que nele há um padrão musical sempre idêntico, monótono, cujas únicas variações acontecem apenas com fins publicitários.

A diferença entre a coisificação do homem em Auschwitz e a regressão da audição pela pseudo-universalização da mercadoria é de grau regressivo em direção à barbárie, à destruição da humanidade, à reificação brutal. Por isso, a crítica aguda de Adorno ao princípio identitário que rege a sociedade capitalista prevê, como risco iminente, a repetição de Auschwitz que destruiu todos os que fossem diferentes do padrão ariano-nazista (judeus, homossexuais, intelectuais, comunistas).

Em "Lírica e sociedade" (ADORNO, 1983b), Adorno apresenta a lírica (objeto delicado) como um discurso avesso à socialização, expressão da subjetividade do sujeito. A expressão individualizada para se tornar universal, no entanto, deve expressar-se na linguagem, que vai além da individualidade. $\mathrm{Na}$ lírica, assim, a elevação ao universal é a manifestação de algo ainda não desfigurado, não captado, não subsumido ao conceito universal (ADORNO, 1983b), pois o poeta é um dos poucos capaz de mergulhar em si e expressar sua subjetividade, encontrando o universal.

As obras de arte, todavia, têm sua grandeza unicamente em deixarem falar aquilo que a ideologia esconde. Seu próprio êxito, que elas o ambicionem ou não, passa além da falsa consciência. (ADORNO, 1983b) 
Importa observar que a qualidade da obra em Adorno é medida, assim como em Lukács, por sua capacidade de expressar o que está além ou aquém da ideologia, revelando o que ela esconde. Na leitura de Lukács, a ideologia não permite a visão do todo, cabendo ao romancista recompô-lo. ${ }^{4} \mathrm{Na}$ perspectiva de Adorno, é o contrário. Não há mais possibilidade de totalidade, a superação crítica dá-se pelo destaque ao que escapa à totalidade: no fragmento, no resíduo, no resto, na sobra, no elemento estranho, no que não está subsumido. Enfim, a capacidade subjetiva revela-se autêntica apenas quando escapa ao padrão identitário, quando não se enquandra.

A universalidade do poema é sempre social. Não é possível um salto direto da expressão lírica para o universal, pois então seria uma revelação de ordem sagrada. O todo da sociedade, como unidade contraditória, aparece dentro da obra, mas deve ser analisado de modo imanente. Ele não revela apenas a ideologia, como falsa consciência ou mentira, mas mostra aquilo que a ideologia esconde. Por isso, Adorno enfatiza que esse saber só é válido quando se redescobre no puro abandonar-se à coisa mesma, na medida que o sujeito ao abandonar-se à coisa em si, é capaz de descobrir as marcas estranhas e diferentes que não se assemelham à ideologia.

Seu distanciamento da mera existência torna-se a medida do que há nesta de errado e de ruim. Em protesto contra ela o poema enuncia o sonho de um mundo que seria diferente. A idiossincrasia do espírito lírico contra a prepotência das coisas é uma forma de reação à coisificação do mundo, à dominação de mercadorias sobre homens que se difundiu desde o começo da idade moderna e que desde a revolução industrial se desdobrou em poder dominante da vida. (ADORNO, 1983b)

O conceito tradicional de lírica é também socialmente determinado, já que a exigência da palavra virginal é em si mesma social. Assim, o desligamento da objetividade, da coerção, do reino da necessidade para uma livre expressão do espírito são marcas da posição social do discurso lírico. A partir do século XIX, a lírica romântica busca a expressão da autêntica natureza humana, resgatando a supremacia da subjetividade sobre o mundo desencantado. Essa seria uma forma

4 Para efeito de exemplificação podemos pensar nos ensaios "Narrar ou descrever" ou "Introdução aos estudos estéticos de Marx e Engels”. 
de revolta em que se procura estabelecer na poesia o encantamento perdido de um mundo em que a divisão do trabalho fez com que o homem perdesse o domínio sobre as atividades concretas, tornando-as meramente abstrações e a si mesmo um ser mutilado. Desse modo, a primazia do sujeito no discurso lírico funciona como contrapartida da sua coisificação na realidade objetiva, desencantada posto que baseada na separação entre sujeito e objeto.

Por isso a lírica se mostra mais profundamente garantida socialmente ali onde não fala segundo o paladar da sociedade, onde nada comunica, onde, ao contrário, o sujeito, que acerta com a expressão feliz, chega ao pé de igualdade com a própria linguagem, ao ponto onde esta, por si mesma, gostaria de ir. (ADORNO, 1983b)

O afastamento e o isolamento do poeta são, assim, socialmente motivados, principalmente considerando a sociedade capitalista que está baseada na atomização individualista, cuja falsa mediação entre as pessoas é a mercadoria. O lírico é, portanto, levado pela sociedade ao isolamento. No caso romântico, existe a busca da conciliação através da arte, como se ausência de violência do momento estético levasse à eliminação da barbárie real. No caso moderno, a lírica é o testemunho de sua impossibilidade, em que a arte é a consciência da infelicidade do homem, é a experiência do sofrimento, através da capacidade de exprimir o singular que não está subsumido pela ideologia, pela falsa universalidade do capital.

A linguagem, na medida em que é dupla, serve de mediação entre a lírica e a sociedade. Através de suas configurações, segundo Adorno, ela se molda inteiramente às emoções subjetivas; um pouco mais, e se poderia chegar a pensar que somente ela as faz brotar e amadurecer. Mas ela continua a ser, por outro lado, o meio dos conceitos, aquilo que restabelece a referência irrenunciável ao universal e à sociedade. Assim, quando o sujeito esquece de si mesmo ele abre a possibilidade de que a linguagem seja resgatada no seu valor humano.

Ao mesmo tempo, a linguagem, como expressão subjetiva, não pode ser absolutizada como sagrada, porque ela não existe de modo independente e externo ao indivíduo, mas faz parte do sujeito. Assim, o auto-esquecimento não é o sacrifício porque não tem o caráter de violência ritual, em que se resgata o valor do ser. É o instante de conciliação, uma pausa momentânea do processo. 
O sujeito não é nem um ser fechado que se baste a si mesmo, que possa negar a sociedade; nem é um ser que funciona apenas como parte determinada da sociedade. Ele nega ambos os lados porque não aceita o isolamento, o rompimento da ligação entre indivíduo e sociedade. Assim, a lírica promove pela linguagem a conciliação entre ambas, um equilíbrio momentâneo e frágil.

A subjetividade lírica deve sua própria existência ao privilégio: somente a pouquíssimos seres humanos foi dado, a despeito da pressão da necessidade vital, captar o universal no mergulho em si mesmos ou, mesmo, simplesmente desenvolver-se como sujeitos autônomos, mestres da livre expressão de si mesmos. (ADORNO, 1983b)

Os outros, não privilegiados, são como objetos. Estão submetidos às contigências materiais das quais não se distanciam e nas quais caem alienados. Eles também têm, no entanto, a necessidade inalienável de expressar a subjetividade, mesmo que de modo fragmentário. O frágil lugar da lírica fica garantido por sua força, por sua capacidade de resistência à totalidade, dando vazão à expressão às individualidades mutiladas.

Em "O ensaio como forma" (ADORNO, 1986b), Adorno afirma a diferença do ensaio em relação à poesia por não ser arte, mas produto da reflexão. Ambos, no entanto, possuem alguns traços em comum. O primeiro é o de expressarem o não-idêntico, aquilo que escapa ao padrão linear e totalizador do pensamento de origem cartesiana. Um segundo é a capacidade de abandonar-se à coisa mesma como descoberta, preferindo sempre o parcial, o particular, sempre aquilo que escapa ao pensamento sistemático, seja de origem empirista seja racionalista.

O caráter de novidade do ensaio está na sua forma. Ele não cria nada de novo, mas sempre revê o já existente, procurando um novo modo de abordálo. A questão não é, então, encontrar a origem do objeto para explicá-lo, mas colocar variações em torno do mesmo, para projetar as suas possibilidades futuras. Sua construção não se dá por definições claras, nem por listagens exaustivas de características, nem por partir do mais simples. O ensaio como forma nega os princípios cartesianos do Discurso do método para se debruçar sobre o objeto mais complexo. O método de abordagem é a negação sistemática de todo método, colocando os conceitos sem os definir. Como em um 
mosaico, uns definem os outros por relação. Seu maior rigor está, então, na composição não para persuadir seu interlocutor (como na retórica), mas para mostrar o caminho da descoberta enquanto acontece, bem como os momentos de beleza que são instantes construídos de felicidade.

Já que, segundo o dito de Hegel, não há nada entre o céu e a terra que não seja mediado, o pensamento só pode ser fiel à idéia de imediatez através do mediado, tornando-se vítima da mediação assim que aborda o imediato de modo imediato. (ADORNO, 1986b: 183)

Talvez a frase mais reveladora do "O ensaio como forma” esteja na citação de Hegel. A luta de Adorno está em desfazer o caráter natural e necessário com que a ideologia se apresenta (imediato-mediatizado); ou de outro modo, indicar como as pessoas pensam, sendo pensadas pela ideologia, e ainda assim consideram estar pensando. A questão nuclear está na necessidade do ensaio de se mostrar como mediação. Adorno nega a radical afirmação idealista de que a ordem das idéias seria a mesma da ordem das coisas. Põe como inaceitável a afirmação empirista de que o fenômeno sempre novo e inalcançável vai além do conceito. Ambos erigem-se dogmaticamente como métodos únicos de acesso à verdade. Em ambos os casos, a reificação do pensamento se faz presente, pois no idealismo fica-se na contemplação vazia dos objetos; e no empirismo, método científico experimental, o sujeito fica completamente alienado do objeto.

Adorno, em contraposição, propõe a mediação dialética entre ambas as esferas (das coisas e das idéias) que transforma o mundo das idéias e forma a própria natureza dos fenômenos. O pensar filosófico surge do olhar demorado e paciente lançado sobre o objeto (cf. ADORNO, 1984; 1995b), à procura do conteúdo de verdade, e que exige sempre voltar ao contato direto com a coisa em si. Aí está a coragem do pensamento, capaz de resistir ao previamente pensado, mostrando a experiência, o contato entre o próprio processo de reflexão e a coisa. O caráter de mediação, no ensaio, fica explicitado na forma aberta ao novo e ao heterogêneo e na forma fechada preocupada com o modo de apresentação.

Essa preocupação de Adorno com a mediação reaparece também no ensaio "Posição do narrador no romance contemporâneo" (ADORNO, 1983c). 
O ponto de partida é a desintegração da identidade da experiência. Narrar significa ter algo especial a dizer, mas o mundo administrado e estandartizado acaba com a unidade, com a experiência individual. O que rege aqui também é abstração da mercadoria, da falsa universalidade, pois o mesmo mundo está na música, na lírica e no ensaio. Assim, no romance, a fidelidade do realismo deve corresponder ao abandono da forma realista, porque reproduz a fachada, com aparência de totalidade sem fissuras, servindo apenas para enganar. Nesse romance de linhagem tradicional, a ficção assemelha-se ao palco italiano que constrói no teatro a ilusão de realidade, mantendo o espectador a uma distância fixa e invariável. No romance contemporâneo, através da revelação da forma de produção, a ilusão de ficcionalidade é quebrada e o leitor é posto em uma distância móvel da ficção. O narrador aparece, nesse caso, como a figura mediadora por excelência, que revela o caráter não imediato da experiência estética, mostrando o próprio laboratório de sua produção.

$\mathrm{Na}$ definição contemporânea da arte pura, como uma entidade a-histórica, há a construção ideológica de um caráter imediato, que anula a sua condição histórica. Para Adorno, tal conceito liga-se ao comportamento regressivo perante a arte. A obra é vista como uma fonte de prazer, um objeto a ser usado como veículo das sensações do indivíduo. É uma paródia da aparência estética, pois o objeto é destruído ou desprezado em sua autonomia, para vir a primeiro plano o prestígio que dá, o deleite que proporciona ou sua natureza mesma de mercadoria. Desse modo, o conceito de arte pura converte-se em um instrumento falacioso para esconder o caráter de mercadoria, falsa mediação, que assume o objeto artístico na sociedade industrializada. A arte verdadeiramente moderna vai nesse caso negar essa homogeneidade, será explosiva, desagregadora, revelando o próprio processo de sua construção, o próprio esforço e sofrimento que a engendrou.

Há que se marcar a diferença entre Auschwitz e a música de consumo, pois o terror social é muito mais grave, de uma violência física absurda, do que a a expressão estética ainda que mutilada na forma do consumo. É de se salientar que Adorno identifica em ambos a marca do mundo administrado, da realidade que tem como princípio de falsa mediação a mercadoria, levando o homem à coisificação e à desumanização. A separação do sujeito e do objeto os torna coisificados, reificados. Assim, a frieza e a indiferença produziram não apenas a música de consumo, expressão do sujeito desagregado, mas 
também, em um grau mais elevado, a barbárie dos campos de concentração. Em contraposição a isto, Adorno defende a educação voltada para a autonomia do sujeito, para sua liberdade. Dentro dessa experiência positiva, estão o ensaio (como reflexão defensora da diferença), a lírica (como resgate da experiência singular como universal) e o romance contemporâneo (como revelação do laboratório ficcional, um choque desalienador).

A dialética e a mediação surgem da mesma realidade, em que a totalidade se mostra como falsidade, mas interessa lembrar que Adorno insiste na distinção entre a arte e a filosofia, por terem natureza e forma diferentes. Tanto em Dialética negativa, quanto em "O ensaio como forma”, a reflexão filosófica afirma-se por sua capacidade de desligar-se da imediatez do fenômeno através do conceito. Ela não se distancia do objeto, nem se despreocupa da forma de expressão, mas não deixa de ser importante construir conceitos que remetam para além de si mesmos, para não se cair no irracionalismo. De outra parte, a arte, como mostra Rodrigo Duarte (1994), ocupa um lugar central nas reflexões de Adorno porque ela consegue ir além da totalidade, da ideologia, para representar o humano ainda não desfigurado pela totalidade. Ela funciona como o outro da realidade, na sua capacidade de se desligar do cotidiano, ao apontar para uma representação do homem conciliado, em que a natureza redimida não esteja dominada. O modo de realizar isto atualmente, ainda segundo Adorno, é abandonar a mímese realista (como crença na objetividade especular da prosa), a expressão sentimental e autêntica da lírica e a harmonia musical. Se a arte se prende à espontaneidade e à irracionalidade, acaba por se tornar expressão do mesmo.

Com isso, chega-se a uma distinção importante para Adorno entre a arte e os objetos da indústria cultural. A reflexão filosófica tem a obrigação de tomar ambas como objeto. Na música de consumo, ela encontra a expressão da identidade ao mesmo, à sociedade de consumo e ao indivíduo desintegrado, enfim, a expressão da barbárie. Na arte, ela encontra o estranho, o diferente, a não-identidade, a humanidade ainda não subsumida pela totalidade: "Só a filosofia pode e deve empreender o esforço de superar o conceito por meio do conceito." (ADORNO, 1984: 24, tradução minha). ${ }^{5}$ Esta reflexão de Adorno é de fundamental importância para a teoria da literatura. De um lado, mantém

5 "Sólo la filosofia puede y debe emprender el esfuerzo de superar el concepto por medio del concepto". 
a necessidade do conceito, do pensamento sistemático (ou negação sistemática de todo método), mas de outro aponta para a necessidade de superá-lo, de encontrar a realidade para além do sistema. Adorno constantemente lembra que a origem da racionalidade e da moral está na irracionalidade, com isso enfatizando a necessidade da auto-reflexão filosófica, em que a teoria não esqueça os seus limites.

No mesmo sentido, ainda em Dialética negativa, Adorno afirma que o menor traço de diferença é o suficiente para destruir a identidade e a totalidade. Desse modo, a reflexão teórica, no meu entender, torna-se extremamente produtiva ao centrar-se naquilo que escapa aos conceitos, pois é ali que se pode encontrar o diferente, o "não-idêntico", ou, em outros termos, o humano não desfigurado pela ideologia.

\section{Referências Bibliográficas}

ADORNO, Theodor. Teoria estética. Lisboa: Edições 70, s.d.

. Fetichismo da música. In: BENJAMIN, Walter et al. Textos escolbidos. São

Paulo: Abril Cultural, 1983a (Os Pensadores).

. Lírica e Sociedade. In: BENJAMIN, Walter et al. Textos escolbidos. São Paulo:

Abril Cultural, 1983b (Os Pensadores).

. Posição do narrador no romance contemporâneo. In: BENJAMIN, Walter et

al. Textos escolhidos. São Paulo: Abril Cultural, 1983c (Os Pensadores).

- Dialética negativa. Madrid: Taurus, 1984.

. Educação após Auschwitz. In: COHN, Gabriel. Theodor W. Adorno: sociolo-

gia. São Paulo: Ática, 1986a (Grandes Cientistas Sociais, 54).

. O ensaio como forma. In: COHN, Gabriel. Theodor W. Adorno: sociologia.

São Paulo: Ática, 1986b (Grandes Cientistas Sociais, 54).

. Teses sobre sociologia da arte. In: COHN, Gabriel. Theodor W. Adorno: socio-

logia. São Paulo: Ática, 1986c (Grandes Cientistas Sociais, 54).

- Minima moralia. São Paulo: Ática, 1993.

Tempo livre. In: Palavras e sinais: modelos críticos 2. Petrópolis, RJ:

Vozes, 1995a.

- Observações sobre o pensamento filosófico. In: Palavras e sinais:

modelos críticos 2. Petrópolis, RJ: Vozes, 1995b.

ADORNO, Theodor; HORKHEIMER, Max. Dialética do esclarecimento. 3. ed. Rio de Janeiro: Jorge Zahar, 1985. 
AMEY, Claude. Experiência estética e agir comunicativo. Novos estudos, São Paulo: CEBRAP, v. 29, mar. 1991.

DUARTE, Rodrigo. Seis nomes, um só Adorno. In: NOVAES, Adauto (Org.). Artepensamento. São Paulo: Companhia das Letras, 1994.

EAGLETON, Terry. Arte depois de Auschwitz: Theodor Adorno. In: A idelogia da estética. Rio de Janeiro: Jorge Zahar, 1993.

GAGNEBIN, Jeanne Marie. Sete aulas sobre linguagem, memória e história. Rio de Janeiro: Imago, 1997.

HABERMAS, Jürgen. Discurso filosófico da modernidade. Lisboa: Dom Quixote, 1990.

JAMESON, Fredric. Marxismo e forma: teorias dialéticas da Literatura no século XX. São Paulo: Hucitec, 1985.

- O marxismo tardio: Adorno, ou a persistência da dialética. São Paulo: Ed. Unesp; Boitempo, 1997. 1996.

Pós-modernismo: a lógica cultural do capitalismo tardio. São Paulo: Ática,

LÖWY, Michael. A escola de Frankfurt e a modernidade. Novos estudos, São Paulo: CEBRAP, v. 32, mar. 1992.

MATOS, Olgária. Arcanos do inteiramente outro: a escola de Frankfurt, a melancolia e a revolução. São Paulo: Brasiliense, 1989.

TERTULIAN, Nicolas. Lukács, Adorno et la philosophie classique allemande. Archives de Philosophie, Paris: CNRS, v. 47, cahier 2, 1984. 